\title{
Plasma Metabolomics Signature of Gout and Asymptomatic Hyperuricemia
}

\section{Baoyu Zhang}

Beijing Lu He Hospital, Capital Medical University

Lijie Zhang

Beijing Lu He Hospital, Capital Medical University

\section{Yuan Wang}

Beijing Lu He Hospital, Capital Medical University

\section{Zongwei Wang}

Beijing Lu He Hospital, Capital Medical University

Caiyan Mo

Beijing Lu He Hospital, Capital Medical University

\section{Bin Cao}

Beijing Lu He Hospital,Capital Medical University

Ruili Yin

Beijing Lu He Hospital, Capital Medical University

Jing Ke

Beijing Lu He Hospital, Capital Medical University

Longyan Yang ( $\sim$ lyyang15@ccmu.edu.cn )

Beijing Lu He Hospital

\section{Dong Zhao}

Beijing Lu He Hospital, Capital Medical University

\section{Research article}

Keywords: Gout, Metabolomics, High performance liquid chromatography-diode array detector, Hyperuricemia

Posted Date: July 17th, 2020

DOI: https://doi.org/10.21203/rs.3.rs-39017/v1

License: () (1) This work is licensed under a Creative Commons Attribution 4.0 International License. Read Full License 


\section{Abstract}

Background: Gout is a metabolic disease and is the most common form of inflammatory arthritis affecting men. However, the pathogenesis of gout is still uncertain, and novel biomarkers are needed for early prediction and diagnosis of gout. To reveal the metabolic alterations in plasma of gout patients and hyperuricemia patients and discover novel molecular biomarkers for early diagnosis. Metabonomics was employed to screen and identify novel biomarkers of gout based on human plasma. High performance liquid chromatography-diode array detector (HPLC-DAD) and orthogonal signal correction partial least squares discriminate analysis (OPLS-DA) were also used for metabonomics study.

Results: 80 and 62 features were selected as remarkable significant variables in the two modes between gout and control group, 90 and 50 features between hyperuricemia (HUA) and control group, 63 and 60 features between gout and HUA group, respectively. 25 potential metabolic biomarkers which at least in two comparison groups were remained. Among 25 metabolites, $34 \%$ presented high area under the curve (AUC) values (AUC >0.75). Four metabolites including Lys-Ser, L-Pipecolic acid, glycine, arecoline were screened out. They were used to distinguish gout from hyperuricemia with $A U C>0.75$, which was greater than the AUC of uric acid.

Conclusion: The differential metabolites of gout screened out were involved in amino acid metabolism, including glycine, serine and threonine metabolism, arginine biosynthesis, glutathione metabolism. Lys-Ser, L-pipecolic acid, glycine, arecoline were downregulated in gout patients compared with hyperuricemia patients. The metabolomics signatures could serve as an efficient tool for early diagnosis and provide novel insights into the pathogenesis of gout.

\section{Background}

Gout is inflammatory arthritis caused by the deposition of monosodium urate crystals in the joints[1]. Its prevalence has dropped from $0.1 \%$ to about $10 \%$ globally, with 0.3 to 6 new gout patients per 1,000 people per year[2]. The prevalence and incidence of gout are increasing in both developed and developing countries[3]. More than $90 \%$ of gout patients are accompanied by kidney disease, often with hyperlipidemia, hypertension, diabetes, arteriosclerosis, coronary heart disease, cardiac insufficiency, and stroke, which seriously threaten the patient's quality of life.

The main pathological feature of gout is that in the case of elevated serum uric acid, chronic monosodium urate crystals deposit in the joints and ligaments[4]. Serum urate level is a strong nonlinear concentration-dependent predictor of acute gout onset, but uric acid level does not predict the risk of gout. Results of a prospective study showed that the cumulative incidence of gout over 15 years was $9 \%$ (baseline serum uric acid levels between $6.0 \mathrm{mg} / \mathrm{dl}$ and $6.9 \mathrm{mg} / \mathrm{dl}$ ) to $49 \%$ (baseline serum uric acid levels > $10 \mathrm{mg} / \mathrm{dl}$ ). In other words, even among patients with a serum urate concentration of $10 \mathrm{mg} / \mathrm{dL}$, only about half of them developed clinical symptoms of gout for more than 15 years. This suggests that long-term hyperuricemia and other factors may be involved in the pathogenesis of gout, and we only have a partial understanding of the risk factors of gout[5]. Hyperuricemia is necessary to cause gout, but not enough to cause symptomatic gout.

More and more evidence shows that gout is a chronic metabolic disease caused by a combination of genetic, environmental, and lifestyle factors. Predicting the risk of gout and reducing the incidence of gout requires a method that can reflect the combined effects of genetics, environment, and lifestyle factors. Metabolomics is a high-throughput technology that captures an individual's systemic metabolic state by simultaneously analyzing a wide range of low-molecular-weight compounds (metabolites) in biological samples. Using metabolomics to detect and analyze metabolites of biological fluids such as urine and blood, it is possible to have a new understanding of the biochemical changes accompanying the occurrence and development of diseases, and then to discover biomarkers and the molecular mechanism of pathology related to the early occurrence of diseases, finally achieves the purpose of guiding clinical diagnosis.

Recently, several studies have reported the preliminary application of metabolomics in gout. Most of these studies were based on gas chromatography-mass spectrometer (GC-MS) or nuclear magnetic resonance (NMR) spectroscopy platforms[6-9]. Very few studies have applied a more sensitive metabolomics platform, ultraperformance liquid chromatography-mass spectrometry (UPLC-MS). Most studies compared the difference in metabolites between gout and normal controls. In the present study, we 


\section{Results}

\section{Demographic characteristics of the study participants}

Totally, 30 male gout patients,30 age and body mass index (BMI)-matched hyperuricemia patients and 30 healthy controls (HCs) were included in this study. The average age of the participants was $33.78 \pm 9.05$ years and the mean BMl years was $25.50 \pm$ $2.90 \mathrm{~kg} / \mathrm{m} 2$. Gout patients and hyperuricemia patients had higher systolic blood pressure (SBP), uric acid (UA), glucose (GLU) and albumin (ALB) compared with healthy controls. Hyperuricemia patients had higher alanine transaminase (ALT) and triglyceride (TG) compared with healthy controls. Demographic characteristics of gout patients, hyperuricemia patients and healthy controls were shown in Table 1. 
Table 1

Demographic characteristics of gout patients, hyperuricemia patients and healthy controls

\begin{tabular}{|c|c|c|c|c|}
\hline & Control & Gout & HUA & $\mathbf{P}$ \\
\hline $\mathrm{N}$ & 30 & 30 & 30 & \\
\hline Age $($ mean $\pm S D)$ & $33.90 \pm 8.09$ & $32.97 \pm 9.20$ & $34.47 \pm 10.01$ & 0.724 \\
\hline $\mathrm{BMI}($ mean $\pm \mathrm{SD})$ & $25.24 \pm 3.21$ & $25.81 \pm 2.63$ & $25.45 \pm 2.91$ & 0.652 \\
\hline Mean SBP(mmHg) & $114.73 \pm 16.34$ & $120.33 \pm 7.90$ & $119.97 \pm 8.84$ & $0.011 * \#$ \\
\hline Mean DBP(mmHg) & $73.23 \pm 8.47$ & $80.70 \pm 6.52$ & $78.47 \pm 4.90$ & $0.012^{\star}$ \\
\hline WBC(10^9/L) & $6.72 \pm 1.60$ & $7.72 \pm 1.81$ & $6.28 \pm 1.85$ & $0.005 \triangle$ \\
\hline $\mathrm{HGB}(\mathrm{g} / \mathrm{L})$ & $153.87 \pm 11.06$ & $152.44 \pm 10.40$ & $152.28 \pm 11.90$ & 0.975 \\
\hline $\operatorname{PLT}\left(10^{\wedge} 9 / \mathrm{L}\right)$ & $243.20 \pm 53.07$ & $229.68 \pm 59.98$ & $238.06 \pm 52.25$ & 0.548 \\
\hline $\mathrm{TP}(\mathrm{g} / \mathrm{L})$ & $73.67 \pm 3.92$ & $75.71 \pm 4.02$ & $74.65 \pm 4.27$ & 0.245 \\
\hline $\operatorname{ALB}(g / L)$ & $47.08 \pm 2.34$ & $49.45 \pm 2.43$ & $49.31 \pm 2.76$ & $0.001^{*} \#$ \\
\hline $\operatorname{ALT}(\mathrm{U} / \mathrm{L})$ & $17.30 \pm 6.25$ & $23.07 \pm 11.62$ & $30.67 \pm 22.16$ & $0.002 \#$ \\
\hline AST(U/L) & $18.17 \pm 4.04$ & $20.20 \pm 9.91$ & $21.77 \pm 10.70$ & 0.472 \\
\hline Y-GGT(U/L) & $22.73 \pm 8.16$ & $32.83 \pm 24.92$ & $35.53 \pm 27.13$ & 0.323 \\
\hline $\mathrm{GLU}(\mathrm{mmol} / \mathrm{L})$ & $4.88 \pm 0.39$ & $5.25 \pm 0.42$ & $5.24 \pm 0.50$ & $0.004 * \#$ \\
\hline BUN(mmol/L) & $4.92 \pm 1.07$ & $4.23 \pm 1.11$ & $4.84 \pm 0.94$ & $0.002^{*}$ \\
\hline $\mathrm{Ca}(\mathrm{mmol} / \mathrm{L})$ & $2.39 \pm 0.11$ & $2.41 \pm 0.08$ & $2.39 \pm 0.08$ & 0.630 \\
\hline $\mathrm{P}(\mathrm{mmol} / \mathrm{L})$ & $1.04 \pm 0.16$ & $1.13 \pm 0.13$ & $1.13 \pm 0.15$ & 0.066 \\
\hline UA(umol/L) & $348.13 \pm 50.53$ & $503.03 \pm 82.46$ & $491.77 \pm 58.46$ & $<0.001^{*} \#$ \\
\hline LDH(U/L) & $165.90 \pm 21.72$ & $162.63 \pm 37.87$ & $180.23 \pm 76.24$ & 0.886 \\
\hline $\mathrm{TG}(\mathrm{mmol} / \mathrm{L})$ & $0.89 \pm 0.29$ & $1.10 \pm 0.34$ & $1.25 \pm 0.19$ & $0.003 \#$ \\
\hline TC(mmol/L) & $4.19 \pm 0.57$ & $4.50 \pm 0.60$ & $4.54 \pm 0.82$ & 0.101 \\
\hline $\mathrm{HDL}-\mathrm{C}(\mathrm{mmol} / \mathrm{L})$ & $1.30 \pm 0.19$ & $1.22 \pm 0.23$ & $1.17 \pm 0.19$ & 0.051 \\
\hline LDH-C(mmol/L) & $2.56 \pm 0.52$ & $2.90 \pm 0.52$ & $2.90 \pm 0.69$ & 0.071 \\
\hline \multicolumn{5}{|c|}{$\begin{array}{l}\text { Abbreviations: HC: healthy controls; HUA: hyperuricemia; SBP: systolic blood pressure; DBP: diastolic blood pressure; BMI: } \\
\text { body mass index; WBC: white blood cell; HGB: hemoglobin; PLT: platelet; TP: total protein; ALB: albumin; ALT: alanine } \\
\text { aminotransferase; AST: aspartate aminotransferase; Y-GGT: Y-glutamyl transpeptidase; GLU: glucose: BUN: blood urea } \\
\text { nitrogen; Ca: calcium; P: phosphorus; UA: Uric acid; LDH: lactate dehydrogenase; TG: Triglycerides; TC: total cholesterol; HDL } \\
\text { C: high-density lipoprotein; LDL-C: low-density lipoprotein cholesterol. }\end{array}$} \\
\hline \multicolumn{5}{|c|}{ * HCs vs Gout $p<0.05 ;$ \# HCs vs HUA $p<0.05 ; \triangle$ Gout vs HUA $p<0.05$} \\
\hline
\end{tabular}

\section{Identification of plasma differential metabolites}

A total of 1055 features in positive ion mode and 1608 features in negative ion mode were detected using UPLC-MS. After peak alignment and removal of missing values, 1492 features in positive ion mode and 1589 features in negative ion mode were remained. 
The remaining data were imported into SIMCA-P to conduct multivariate statistical analysis. The principal component analysis (PCA) analysis could outline the original distribution of metabolites. As shown in Fig. 1. a and h, there were no obvious outlier samples in modes. However, the scatter plot failed to show a clear separation in modes. Then, the OPLS-DA model was used to characterize the metabolic disturbances (Fig. 2. a and f). Gout samples or HUA samples could be clearly distinguished from healthy control samples of positives and negative ion modes, but a small number of score plots crossed between gout group and HUA group. Permutation plots of two OPLS-DA models repeated 200 times verified the validation of the models (Fig. 3. a and f). All the permuted R2 (cum) and Q2 (cum) values to the left were lower than the original point to the right and all the regression lines of the Q2 (cum) points have a negative intercept[10,11], which indicates that the models were valid with no overfitting.

The standard value used in this project was that the P-value $<0.05$, and Variable Importance in the Projection (VIP) value $>1.0,80$ and 62 features were selected as remarkable significant variables in the two modes between gout and control group, 90and 50 features between HUA and control group, 63 and 60 features between gout and HUA group, respectively (Fig. 4. a and f). For each group of comparison, the Euclidean Distance matrix was calculated for the quantitative values of the differential metabolites, and the differential metabolites were clustered by using the full linkage method, and the heatmap was used to demonstrate (Fig. 5. a and f).

According to fold change $>1.2$ or $<0.83,25$ potential metabolic biomarkers which at least in two comparison groups were remained. The Human Metabolome Database (HMDB) identifier, variable importance in projection values, P-values, fold change and AUC of each metabolite are shown in detail (Table 2.) The differential metabolites can be categorized as amino acids, purine derivatives, fatty acyls, carboxylic acids and derivatives. 
Table 2

Significantly altered plasma metabolites of patients comparing toeachothergroup.

\begin{tabular}{|c|c|c|c|c|c|c|c|c|c|}
\hline model & Metabolites & HMDB & VIP & $\mathbf{P}$ & FC & compare & AUC & $95 \% \mathrm{CL}$ & Sub-CLASS \\
\hline $\mathrm{N}$ & Thymine & HMDB00262 & 2.67 & 1.07E-09 & 0.49 & $\begin{array}{l}\text { Gout- } \\
\text { Control }\end{array}$ & 0.949 & $\begin{array}{l}0.895- \\
1.0\end{array}$ & Diazines \\
\hline$N$ & $\begin{array}{l}\text { Sphingosine-1- } \\
\text { phosphate }\end{array}$ & & 2.22 & $2.16 \mathrm{E}-07$ & 0.73 & $\begin{array}{l}\text { Gout- } \\
\text { Control }\end{array}$ & 0.864 & $\begin{array}{l}0.774- \\
0.955\end{array}$ & \\
\hline$N$ & Pyruvate & HMDB00243 & 1.82 & 0.000524 & 0.71 & $\begin{array}{l}\text { Gout- } \\
\text { Control }\end{array}$ & 0.777 & $\begin{array}{l}0.657- \\
0.896\end{array}$ & Alpha keto acids \\
\hline$N$ & $\begin{array}{l}\text { Monomethyl } \\
\text { glutaric acid }\end{array}$ & HMDB00858 & 1.47 & 0.041338 & 1.25 & $\begin{array}{l}\text { Gout- } \\
\text { Control }\end{array}$ & 0.654 & $\begin{array}{l}0.523- \\
0.799\end{array}$ & Fatty Acyls \\
\hline $\mathrm{N}$ & L-Malic acid & HMDB00156 & 2.41 & 2.3E-08 & 0.52 & $\begin{array}{l}\text { Gout- } \\
\text { Control }\end{array}$ & 0.884 & $\begin{array}{l}0.804- \\
0.965\end{array}$ & $\begin{array}{l}\text { Fatty acids and } \\
\text { conjugates }\end{array}$ \\
\hline$N$ & Hypoxanthine & HMDB00157 & 1.80 & 0.002279 & 2.17 & $\begin{array}{l}\text { Gout- } \\
\text { Control }\end{array}$ & 0.741 & $\begin{array}{l}0.618- \\
0.864\end{array}$ & $\begin{array}{l}\text { Purines and } \\
\text { purine } \\
\text { derivatives }\end{array}$ \\
\hline $\mathrm{N}$ & $\begin{array}{l}\text { Hydroxyisocaproic } \\
\text { acid }\end{array}$ & HMDB00665 & 1.25 & 0.04152 & 1.26 & $\begin{array}{l}\text { Gout- } \\
\text { Control }\end{array}$ & 0.641 & $\begin{array}{l}0.500- \\
0.782\end{array}$ & Fatty Acyls \\
\hline$N$ & $\begin{array}{l}\text { DL-3-Phenyllactic } \\
\text { acid }\end{array}$ & HMDB00779 & 1.40 & 0.009984 & 1.23 & $\begin{array}{l}\text { Gout- } \\
\text { Control }\end{array}$ & 0.661 & $\begin{array}{l}0.523- \\
0.793\end{array}$ & $\begin{array}{l}\text { Phenylpropanoic } \\
\text { acids }\end{array}$ \\
\hline$N$ & Cysteine-S-sulfate & HMDB00731 & 2.12 & $2.11 \mathrm{E}-07$ & 2.16 & $\begin{array}{l}\text { Gout- } \\
\text { Control }\end{array}$ & 0.86 & $\begin{array}{l}0.752- \\
0.968\end{array}$ & $\begin{array}{l}\text { Carboxylic acids } \\
\text { and derivatives }\end{array}$ \\
\hline $\mathrm{N}$ & $\begin{array}{l}\text { Cyclopiazonic } \\
\text { Acid }\end{array}$ & & 1.39 & 0.049818 & 0.69 & $\begin{array}{l}\text { Gout- } \\
\text { Control }\end{array}$ & 0.701 & $\begin{array}{l}0.566- \\
0.837\end{array}$ & \\
\hline $\mathrm{N}$ & Cortisone acetate & & 2.25 & 0.000501 & 1.92 & $\begin{array}{l}\text { Gout- } \\
\text { Control }\end{array}$ & 0.814 & $\begin{array}{l}0.705- \\
0.924\end{array}$ & \\
\hline $\mathrm{N}$ & Thymine & HMDB00262 & 2.99 & $8.4 \mathrm{E}-10$ & 0.49 & $\begin{array}{l}\text { HUA- } \\
\text { Control }\end{array}$ & 0.97 & $\begin{array}{l}0.933- \\
1.0\end{array}$ & Diazines \\
\hline $\mathrm{N}$ & $\begin{array}{l}\text { Sphingosine-1- } \\
\text { phosphate }\end{array}$ & & 1.61 & 0.000633 & 0.80 & $\begin{array}{l}\text { HUA- } \\
\text { Control }\end{array}$ & 0.747 & $\begin{array}{l}0.620- \\
0.874\end{array}$ & \\
\hline $\mathrm{N}$ & Pyruvate & HMDB00243 & 1.97 & 0.000399 & 0.70 & $\begin{array}{l}\text { HUA- } \\
\text { Control }\end{array}$ & 0.791 & $\begin{array}{l}0.675- \\
0.907\end{array}$ & Alpha keto acids \\
\hline$P$ & Pro-Glu & & 1.47 & 0.039555 & 1.99 & $\begin{array}{l}\text { HUA- } \\
\text { Control }\end{array}$ & 0.687 & $\begin{array}{l}0.551- \\
0.822\end{array}$ & \\
\hline$P$ & Pro-Ala & & 1.25 & 0.00491 & 1.86 & $\begin{array}{l}\text { HUA- } \\
\text { Control }\end{array}$ & 0.657 & $\begin{array}{l}0.512- \\
0.802\end{array}$ & \\
\hline$P$ & Ornithine & HMDB00214 & 1.13 & 0.015229 & 1.71 & $\begin{array}{l}\text { HUA- } \\
\text { Control }\end{array}$ & 0.676 & $\begin{array}{l}0.539- \\
0.812\end{array}$ & $\begin{array}{l}\text { Amino acids, } \\
\text { peptides, and } \\
\text { alogues }\end{array}$ \\
\hline$N$ & O-Acetyl-L-serine & HMDB03011 & 1.07 & 0.018987 & 1.28 & $\begin{array}{l}\text { HUA- } \\
\text { Control }\end{array}$ & 0.676 & $\begin{array}{l}0.538- \\
0.813\end{array}$ & $\begin{array}{l}\text { Amino acids, } \\
\text { peptides, and } \\
\text { alogues }\end{array}$ \\
\hline $\mathrm{N}$ & $\begin{array}{l}\text { Monomethyl } \\
\text { glutaric acid }\end{array}$ & HMDB00858 & 1.37 & 0.01396 & 1.31 & $\begin{array}{l}\text { HUA- } \\
\text { Control }\end{array}$ & 0.694 & $\begin{array}{l}0.561- \\
0.827\end{array}$ & Fatty Acyls \\
\hline$N$ & Maleic acid & HMDB00176 & 1.63 & 0.000855 & 1.39 & $\begin{array}{l}\text { HUA- } \\
\text { Control }\end{array}$ & 0.719 & $\begin{array}{l}0.589- \\
0.849\end{array}$ & $\begin{array}{l}\text { Dicarboxylic } \\
\text { acids and } \\
\text { derivatives }\end{array}$ \\
\hline
\end{tabular}

VIP: variable importance in projection; FC: fold change; AUC: area under the curve. a p value was adjusted after controlling the false discovery rate. * The AUC was greater than 0.75 . 


\begin{tabular}{|c|c|c|c|c|c|c|c|c|c|}
\hline model & Metabolites & HMDB & VIP & $P$ & F C & compare & AUC & $95 \% \mathrm{CL}$ & Sub-CLASS \\
\hline $\mathrm{P}$ & Lys-Ser & & 1.56 & 0.009406 & 1.91 & $\begin{array}{l}\text { HUA- } \\
\text { Control }\end{array}$ & 0.663 & $\begin{array}{l}0.523- \\
0.804\end{array}$ & \\
\hline $\mathrm{P}$ & L-Valine & & 2.44 & 1.19E-05 & 1.64 & $\begin{array}{l}\text { HUA- } \\
\text { Control }\end{array}$ & 0.811 & $\begin{array}{l}0.699- \\
0.923\end{array}$ & \\
\hline $\mathrm{P}$ & L-Pipecolic acid & & 2.05 & 0.000427 & 1.92 & $\begin{array}{l}\text { HUA- } \\
\text { Control }\end{array}$ & 0.773 & $\begin{array}{l}0.654- \\
0.893\end{array}$ & \\
\hline$N$ & L-Malic acid & HMDB00156 & 2.82 & 1.47E-07 & 0.53 & $\begin{array}{l}\text { HUA- } \\
\text { Control }\end{array}$ & 0.886 & $\begin{array}{l}0.799- \\
0.972\end{array}$ & $\begin{array}{l}\text { Fatty acids and } \\
\text { conjugates }\end{array}$ \\
\hline$P$ & L-Cysteine & HMDB00574 & 1.17 & 0.011655 & 1.62 & $\begin{array}{l}\text { HUA- } \\
\text { Control }\end{array}$ & 0.682 & $\begin{array}{l}0.541- \\
0.824\end{array}$ & $\begin{array}{l}\text { Amino acids, } \\
\text { peptides, and } \\
\text { alogues }\end{array}$ \\
\hline $\mathrm{P}$ & Ile-Glu & & 1.37 & 0.030944 & 1.82 & $\begin{array}{l}\text { HUA- } \\
\text { Control }\end{array}$ & 0.682 & $\begin{array}{l}0.547- \\
0.818\end{array}$ & \\
\hline$N$ & Hypoxanthine & HMDB00157 & 1.64 & 0.000239 & 2.10 & $\begin{array}{l}\text { HUA- } \\
\text { Control }\end{array}$ & 0.784 & $\begin{array}{l}0.669- \\
0.899\end{array}$ & $\begin{array}{l}\text { Purines and } \\
\text { purine } \\
\text { derivatives }\end{array}$ \\
\hline $\mathrm{N}$ & $\begin{array}{l}\text { Hydroxyisocaproic } \\
\text { acid }\end{array}$ & HMDB00665 & 1.38 & 0.002686 & 1.21 & $\begin{array}{l}\text { HUA- } \\
\text { Control }\end{array}$ & 0.73 & $\begin{array}{l}0.601- \\
0.859\end{array}$ & Fatty Acyls \\
\hline $\mathrm{P}$ & Glycine & HMDB00123 & 2.61 & 0.000184 & 1.50 & $\begin{array}{l}\text { HUA- } \\
\text { Control }\end{array}$ & 0.748 & $\begin{array}{l}0.623- \\
0.872\end{array}$ & $\begin{array}{l}\text { Amino acids, } \\
\text { peptides, and } \\
\text { alogues }\end{array}$ \\
\hline$P$ & Ellipticine & & 1.35 & 0.036375 & 1.76 & $\begin{array}{l}\text { HUA- } \\
\text { Control }\end{array}$ & 0.65 & $\begin{array}{l}0.509- \\
0.791\end{array}$ & \\
\hline $\mathrm{P}$ & D-Ornithine & HMDB03374 & 1.31 & 0.045578 & 1.49 & $\begin{array}{l}\text { HUA- } \\
\text { Control }\end{array}$ & 0.654 & $\begin{array}{l}0.514- \\
0.794\end{array}$ & $\begin{array}{l}\text { Carboxylic acids } \\
\text { and derivatives }\end{array}$ \\
\hline$N$ & $\begin{array}{l}\text { DL-3-Phenyllactic } \\
\text { acid }\end{array}$ & HMDB00779 & 1.15 & 0.006118 & 1.22 & $\begin{array}{l}\text { HUA- } \\
\text { Control }\end{array}$ & 0.692 & $\begin{array}{l}0.553- \\
0.831\end{array}$ & $\begin{array}{l}\text { Phenylpropanoic } \\
\text { acids }\end{array}$ \\
\hline$N$ & Cysteine-S-sulfate & HMDB00731 & 2.75 & $2.26 \mathrm{E}-09$ & 2.68 & $\begin{array}{l}\text { HUA- } \\
\text { Control }\end{array}$ & 0.909 & $\begin{array}{l}0.821- \\
0.997\end{array}$ & $\begin{array}{l}\text { Carboxylic acids } \\
\text { and derivatives }\end{array}$ \\
\hline$N$ & Cortisone acetate & & 1.91 & 0.002905 & 1.54 & $\begin{array}{l}\text { HUA- } \\
\text { Control }\end{array}$ & 0.737 & $\begin{array}{l}0.612- \\
0.862\end{array}$ & \\
\hline $\mathrm{P}$ & Arecoline & HMDB30353 & 2.11 & 0.000413 & 1.53 & $\begin{array}{l}\text { HUA- } \\
\text { Control }\end{array}$ & 0.749 & $\begin{array}{l}0.624- \\
0.873\end{array}$ & \\
\hline$P$ & Pro-Glu & & 2.70 & 0.00675 & 0.37 & $\begin{array}{l}\text { Gout- } \\
\text { HUA }\end{array}$ & 0.718 & $\begin{array}{l}0.588- \\
0.848\end{array}$ & \\
\hline $\mathrm{P}$ & Pro-Ala & & 1.95 & 0.014018 & 0.58 & $\begin{array}{l}\text { Gout- } \\
\text { HUA }\end{array}$ & 0.622 & $\begin{array}{l}0.47- \\
0.774\end{array}$ & \\
\hline$P$ & Ornithine & HMDB00214 & 1.76 & 0.012242 & 0.58 & $\begin{array}{l}\text { Gout- } \\
\text { HUA }\end{array}$ & 0.658 & $\begin{array}{l}0.514- \\
0.801\end{array}$ & $\begin{array}{l}\text { Amino acids, } \\
\text { peptides, and } \\
\text { alogues }\end{array}$ \\
\hline$N$ & O-Acetyl-L-serine & HMDB03011 & 1.16 & 0.003522 & 0.73 & $\begin{array}{l}\text { Gout- } \\
\text { HUA }\end{array}$ & 0.728 & $\begin{array}{l}0.598- \\
0.857\end{array}$ & $\begin{array}{l}\text { Amino acids, } \\
\text { peptides, and } \\
\text { alogues }\end{array}$ \\
\hline $\mathrm{N}$ & Maleic acid & HMDB00176 & 1.50 & 0.006243 & 0.77 & $\begin{array}{l}\text { Gout- } \\
\text { HUA }\end{array}$ & 0.677 & $\begin{array}{l}0.539- \\
0.814\end{array}$ & $\begin{array}{l}\text { Dicarboxylic } \\
\text { acids and } \\
\text { derivatives }\end{array}$ \\
\hline
\end{tabular}

VIP: variable importance in projection; FC: fold change; AUC: area under the curve. a $p$ value was adjusted after controlling the false discovery rate. * The AUC was greater than 0.75 . 


\begin{tabular}{|c|c|c|c|c|c|c|c|c|c|}
\hline model & Metabolites & HMDB & VIP & $\mathbf{P}$ & F C & compare & AUC & $95 \% \mathrm{CL}$ & Sub-CLASS \\
\hline$P$ & Lys-Ser & & 2.16 & 0.001551 & 0.41 & $\begin{array}{l}\text { Gout- } \\
\text { HUA }\end{array}$ & 0.76 & $\begin{array}{l}0.635- \\
0.885\end{array}$ & \\
\hline$P$ & L-Valine & HMDB00883 & 1.66 & 0.001819 & 0.72 & $\begin{array}{l}\text { Gout- } \\
\text { HUA }\end{array}$ & 0.728 & $\begin{array}{l}0.598- \\
0.858\end{array}$ & $\begin{array}{l}\text { Amino acids, } \\
\text { peptides, and } \\
\text { alogues }\end{array}$ \\
\hline$P$ & L-Pipecolic acid & HMDB00716 & 2.21 & 0.000552 & 0.53 & $\begin{array}{l}\text { Gout- } \\
\text { HUA }\end{array}$ & 0.769 & $\begin{array}{l}0.647- \\
0.891\end{array}$ & $\begin{array}{l}\text { Carboxylic acids } \\
\text { and derivatives }\end{array}$ \\
\hline $\mathrm{P}$ & L-Cysteine & HMDB00574 & 1.59 & 0.005312 & 0.61 & $\begin{array}{l}\text { Gout- } \\
\text { HUA }\end{array}$ & 0.659 & $\begin{array}{l}0.507- \\
0.811\end{array}$ & $\begin{array}{l}\text { Amino acids, } \\
\text { peptides, and } \\
\text { alogues }\end{array}$ \\
\hline $\mathrm{P}$ & Ile-Glu & & 2.43 & 0.009806 & 0.48 & $\begin{array}{l}\text { Gout- } \\
\text { HUA }\end{array}$ & 0.69 & $\begin{array}{l}0.555- \\
0.825\end{array}$ & \\
\hline $\mathrm{P}$ & Glycine & HMDB00123 & 1.92 & 0.000156 & 0.67 & $\begin{array}{l}\text { Gout- } \\
\text { HUA }\end{array}$ & 0.767 & $\begin{array}{l}0.648- \\
0.886\end{array}$ & $\begin{array}{l}\text { Amino acids, } \\
\text { peptides, and } \\
\text { alogues }\end{array}$ \\
\hline$P$ & Ellipticine & & 2.41 & 0.010781 & 0.49 & $\begin{array}{l}\text { Gout- } \\
\text { HUA }\end{array}$ & 0.656 & $\begin{array}{l}0.513- \\
0.798\end{array}$ & \\
\hline$P$ & D-Ornithine & HMDB03374 & 2.51 & 0.004196 & 0.56 & $\begin{array}{l}\text { Gout- } \\
\text { HUA }\end{array}$ & 0.699 & $\begin{array}{l}0.565- \\
0.833\end{array}$ & $\begin{array}{l}\text { Carboxylic acids } \\
\text { and derivatives }\end{array}$ \\
\hline$N$ & $\begin{array}{l}\text { Cyclopiazonic } \\
\text { Acid }\end{array}$ & & 2.62 & 0.012678 & 0.52 & $\begin{array}{l}\text { Gout- } \\
\text { HUA }\end{array}$ & 0.742 & $\begin{array}{l}0.616- \\
0.869\end{array}$ & \\
\hline $\mathrm{P}$ & Arecoline & & 1.99 & 0.000183 & 0.64 & $\begin{array}{l}\text { Gout- } \\
\text { HUA }\end{array}$ & 0.76 & $\begin{array}{l}0.637- \\
0.883\end{array}$ & \\
\hline
\end{tabular}

Given the limited diagnostic performances of uric acid, ROC analysis of each metabolite was conducted to seek novel diagnostic biomarkers. Among 25 metabolites, 34\% presented high AUC values (AUC > 0.75). Using uric acid as a diagnostic indicator of hyperuricemia, compared to healthy control, the AUC was 0.991 , no better diagnostic indicator than uric acid among the differential metabolites. But 4 metabolites AUC $>0.8$. Using uric acid as a diagnostic indicator of gout, compared with healthy control, the AUC was 0.948 . If using thymine as a diagnostic indicator of gout, the AUC was 0.949 , and 5 metabolites AUC $>0.8$. If uric acid levels were used as a diagnostic marker to identify patients with gout from hyperuricemia, the AUC $=0.565$, and all metabolites screened out in this study were better than uric acid and 4 metabolites (Lys-Ser, L-Pipecolic acid, glycine, arecoline) AUC > 0.75 (Table 2.). These candidates could be used as novel diagnostic biomarkers.

Compared with hyperuricemia groups, the differential metabolites of gout screened out were involved in amino acid metabolism, including glycine, serine and threonine metabolism, arginine biosynthesis, glutathione metabolism (Fig. 6.)

\section{Discussion}

In this study, we enrolled the patients with hyperuricemia or gout and healthy control group, compared to the difference of plasma metabolites of three groups. Unlike previous studies, this study excluded the obesity, hyperlipidemia, hypertension, etc., which could be better reflect the differences of the above three groups metabolites. We still observed that blood glucose and systolic blood pressure were higher in the gout or hyperuricemia groups than in the healthy controls, which indicated that uric acid was related to glucose and salt metabolism[12-15].

In this study, we were able to discriminate gout patients or hyperuricemia patients from healthy controls in an OPLS-DA model based on plasma metabolites, and 25 significantly different metabolites were identified which were mainly involved in amino acid metabolism, purine metabolism, carbohydrate metabolism. However, many unknown components were still present. The 
identification of these unknown substances using HPLC-MS will be focused on in our future work. But a small number of score plots crossed between gout group and HUA group in an OPLS-DA model. Maybe we need more samples to separate the gout group from HUA group.

LC-MS-based metabolomics was a promising technique for biomarker discovery, which was put into this study, and reinforces the idea. In this study, we found that uric acid was still a biomarker for the diagnosis of hyperuricemia or gout, but it was limited to separate gout from hyperuricemia by uric acid. 4 metabolites including Lys-Ser, L-Pipecolic acid, glycine, arecoline were screen out. They were used to distinguish gout from hyperuricemia with AUC $>0.75$, which was greater than the AUC of uric acid. Most of the metabolic differences found in this study were amino acids, which were different from previous studies. Many of the previous studies were lipid metabolites[7, 9], which might be related to the inclusion criteria of our enrolled population. At the time of entry, we excluded patients with hyperlipidemia.

L-proline is one of the twenty amino acids used in living organisms as the building blocks of proteins. Proline is called an imino acid, although the International Union of Pure and Applied Chemistry (IUPAC) definition of an imine requires a carbon-nitrogen double bond. Proline is a non-essential amino acid that is synthesized from glutamic acid. It is an essential component of collagen and is important for proper functioning of joints and tendons. Joint damage in patients with chronic gout may be associated with down-regulation of L-proline.

Glycine is a simple, nonessential amino acid, although experimental animals show reduced growth on low-glycine diets. The average adult ingests 3 to 5 grams of glycine daily. Glycine is involved in the body's production of DNA, phospholipids and collagen, and in release of energy. Glycine is an amino acid that is a component of endogenous antioxidant reductive glutathione. It is also sometimes referred to as a semi-essential amino acid and is often supplemented externally during severe stress. Recent studies have found that glycine also has anti-inflammatory and immunomodulatory effects, and has a protective effect on arthritis. Compared with patients with hyperuricemia, patients with gout had reduced glycine and reduced protective effect on joints.

Adenosine is a nucleoside that is composed of adenine and D-ribose. Adenosine or adenosine derivatives play many important biological roles in addition to being components of DNA and RNA. For instance, adenosine plays an important role in energy transfer as adenosine triphosphate (ATP) and adenosine diphosphate (ADP). Adenosine is an endogenous purine nucleoside. Adenosine was down-regulated in gout patients compared with patients with hyperuricemia, which indicated that patients with gout have active purine metabolism.

In this study, we also found that the levels of thymine, sphingosine-1-phosphate and pyruvate were significantly lower and with high AUC (AUC > 0.75) in patients with gout or hyperuricemia than in healthy controls, and the levels of L-malic acid and cysteines-sulfate were significantly higher and with high AUC (AUC > 0.75 ) in patients with gout or hyperuricemia than in healthy controls. These metabolites may be biomarkers for the diagnosis of gout and hyperuricemia.

This was a cross-sectional observational study, which found that some metabolites may be used in the diagnosis of gout or hyperuricemia, but the causal relationship cannot be determined. In order to better understand the physiological and pathological mechanisms of gout and hyperuricemia, the mechanism of the role of metabolites in the pathogenesis of gout needs further verification.

\section{Conclusions}

In summary, the present study identified the plasma metabolomics signatures of gout through LC-MS. The differential metabolites of gout screened out were involved in amino acid metabolism, including glycine, serine and threonine metabolism, arginine biosynthesis, glutathione metabolism. Lys-Ser, L-pipecolic acid, glycine, arecoline were down-regulated in gout patients compared with hyperuricemia patients. These results can provide novel insights into the development of gout.

\section{Methods}




\section{Study Design and Population}

This study was an across-sectional observational study. From October 2018 to May 2019, 60 participants and 30 volunteers were enrolled from the outpatient department or hospitalized at the Center for Endocrine Metabolism and Immune Disease Center at

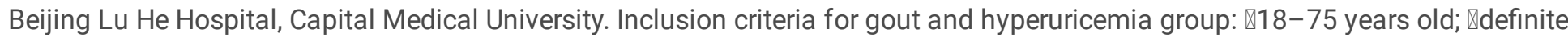
diagnosis of hyperuricemia (serum uric acid $\geq 420 \mu \mathrm{mo} 1 / \mathrm{L}(7 \mathrm{mg} / \mathrm{dl}), \geq 2$ times in the last month; 『willing to participate in this study. The gout group also met the diagnostic criteria of ACR-EULAR gout arthritis. Healthy control group: Normal blood uric acid levels. Exclusion criteria: malignant tumors/hematological tumors; pregnant/lactating women or women planning to become pregnant; chronic renal failure (CKD stage II and above, eGFR $<90 \mathrm{m1} / \mathrm{min} / 1.73 \mathrm{~m}^{2}$ ); abnormal liver function (ALT $\square$ AST $\square \mathrm{GGT} \square T$-Bil $\square$ D-Bil > upper limit of normal value); hyperlipidemia (TG > $1.7 \mathrm{mmol} / \mathrm{l}, \mathrm{CHO}>5.17 \mathrm{mmol} / \mathrm{l}, \mathrm{LDL}>3.36 \mathrm{mmol} / \mathrm{l}$ ); diabetes, hypertension, cardiovascular and cerebrovascular diseases; rheumatic diseases such as rheumatoid arthritis, osteoarthritis, spondyloarthropathy, etc.; have taken the following drugs in the last 6 months: glucocorticoids, immunosuppressants (mercaptopurine, 6-mercaptopurine, cyclosporine, cyclophosphamide), chemotherapy drugs; those who are allergic to drugs such as non-steroidal anti-inflammatory drugs, colchicine, febuxostat, allopurinol, or hypersensitivity; those with severe infections, active tuberculosis; have accepted urate-lowering therapy in the past three months; persons with mental illness who cannot cooperate; combined with other diseases affecting the efficacy or poor compliance.

The healthy control group was age-matched healthy volunteers registered in the physical examination center of Beijing Lu He Hospital. This study was approved by the ethics committee of the Beijing Lu He Hospital, Capital Medical University. Written informed consent was obtained from each subject.

\section{Sample collection and preparation}

Venous plasma samples were collected in K2 EDTA vacutainer tubes from gout patients, hyperuricemia patients and HCs after an overnight fast for at least $8 \mathrm{~h}$ and cooled down in freezer $\left(4^{\circ} \mathrm{C}\right)$ at once. They were then centrifuged at $3000 \mathrm{rpm}$ for $10 \mathrm{~min}$ at $4{ }^{\circ} \mathrm{C}$ within $2 \mathrm{~h}$. Supernatants (plasma) were separated and transferred into new vials, and immediately stored frozen $\left(80^{\circ} \mathrm{C}\right)$ until sample preparation.

Prior to LC-MS analysis, $100 \mu \mathrm{L}$ of sample was transferred to an EP tube, and $400 \mu \mathrm{L}$ extract solution (acetonitrile: methanol $=1: 1$ ) containing internal standard ( $\mathrm{L}-2$-Chlorophenylalanine, $2 \mu \mathrm{g} / \mathrm{mL}$ ) was added. After $30 \mathrm{~s}$ vortex, the samples were sonicated for $10 \mathrm{~min}$ in an ice-water bath. Then the samples were incubated at $-40^{\circ} \mathrm{C}$ for $1 \mathrm{~h}$ and centrifuged at $10000 \mathrm{rpm}$ for $15 \mathrm{~min}$ at $4{ }^{\circ} \mathrm{C}$. $425 \mu \mathrm{L}$ of supernatant was transferred to a fresh tube and dried in a vacuum concentrator at $37^{\circ} \mathrm{C}$. Then, the dried samples were reconstituted in $200 \mu \mathrm{L}$ of $50 \%$ acetonitrile by sonication on ice for $10 \mathrm{~min}$. The constitution was then centrifuged at $13000 \mathrm{rpm}$ for $15 \mathrm{~min}$ at $4{ }^{\circ} \mathrm{C}$, and $75 \mu \mathrm{L}$ of supernatant was transferred to a fresh glass vial for LC/MS analysis. The quality control (QC) sample was prepared by mixing an equal aliquot of the supernatants from all of the samples

\section{UPLC-MS/MS metabolomics profiling}

The UHPLC separation was carried out using a 1290 Infinity series UHPLC System (Agilent Technologies), equipped with a UPLC BEH Amide column $(2.1 * 100 \mathrm{~mm}, 1.7 \mu \mathrm{m}$, Waters). The mobile phase consisted of $25 \mathrm{mmol} / \mathrm{L}$ ammonium acetate and 25 ammonia hydroxide in water $(\mathrm{pH}=9.75)(\mathrm{A})$ and acetonitrile $(\mathrm{B})$. The analysis was carried with elution gradient as follows: $0 \sim$ $0.5 \mathrm{~min}, 95 \% \mathrm{~B} ; 0.5 \sim 7.0 \mathrm{~min}, 95 \% \sim 65 \% \mathrm{~B} ; 7.0 \sim 8.0 \mathrm{~min}, 65 \% \sim 40 \%$ B; $8.0 \sim 9.0 \mathrm{~min}, 40 \% \mathrm{~B} ; 9.0 \sim 9.1 \mathrm{~min}, 40 \% \sim 95 \%$ B; $9.1 \sim$ $12.0 \mathrm{~min}, 95 \% \mathrm{~B}$. The column temperature was $25^{\circ} \mathrm{C}$. The auto-sampler temperature was $4{ }^{\circ} \mathrm{C}$, and the injection volume was $1 \mu \mathrm{L}$ (pos) or $1 \mu \mathrm{L}$ (neg), respectively.

The TripleTOF 6600 mass spectrometry (AB Sciex) was used for its ability to acquire MS/MS spectra on an informationdependent basis (IDA) during an LC/MS experiment. In this mode, the acquisition software (Analyst TF 1.7, AB Sciex) continuously evaluates the full scan survey MS data as it collects and triggers the acquisition of MS/MS spectra depending on preselected criteria. In each cycle, the most intensive 12 precursor ions with intensity above 100 were chosen for MS/MS at 
collision energy (CE) of $30 \mathrm{eV}$. The cycle time was $0.56 \mathrm{~s}$. ESI source conditions were set as follows: Gas 1 as 60 psi, Gas 2 as 60 psi, Curtain Gas as $35 \mathrm{psi}$, Source Temperature as $600^{\circ} \mathrm{C}$, Declustering potential as $60 \mathrm{~V}$, lon Spray Voltage Floating (ISVF) as $5000 \mathrm{~V}$ or $-4000 \mathrm{~V}$ in positive or negative modes, respectively.

\section{Data pre-processing and statistical analysis}

MS raw data (.wiff) files were converted to the mzXML format by ProteoWizard, and processed by R package XCMS (version 3.2). The process includes peak deconvolution, alignment and integration. Minfrac and cut off are set as 0.5 and 0.6 respectively. Inhouse MS2 database was applied for metabolites identification.

In this study, the original data were preprocessed firstly. Then, the missing values were filled up by half of the minimum value. Also, internal standard normalization method was employed in this data analysis. The final dataset containing the information of peak number, sample name and normalized peak area was imported to SIMCA15.0.2 software package (Sartorius Stedim Data Analytics AB, Umea, Sweden) for multivariate analysis. Data was scaled and logarithmically transformed to minimize the impact of both noise and high variance of the variables. After these transformations, PCA, an unsupervised analysis that reduces the dimension of the data, was carried out to visualize the distribution and the grouping of the samples. $95 \%$ confidence interval in the PCA score plot was used as the threshold to identify potential outliers in the dataset. In order to visualize group separation and find significantly changed metabolites, supervised orthogonal projections to OPLS-DA was applied. Then, a 7-fold cross validation was performed to calculate the value of R2 and Q2. R2 indicates how well the variation of a variable is explained and Q2 means how well a variable could be predicted. To check the robustness and predictive ability of the OPLS-DA model, 200 times permutations was further conducted. Afterward, the R2 and Q2 intercept values were obtained. Here, the intercept value of Q2 represents the robustness of the model, the risk of overfitting and the reliability of the model, which will be the smaller the better. Furthermore, the value of variable importance in the projection (VIP) of the first principal component in OPLS-DA analysis was obtained. It summarizes the contribution of each variable to the model. The metabolites with VIP $>1$ and $p<0.05$ (student $t$ test) were considered as significantly changed metabolites. In addition, commercial databases including KEGG(http://www.genome.jp/kegg/) and MetaboAnalyst (http://www.metaboanalyst.ca/) were used for pathway enrichment analysis.

\section{Abbreviations}

High performance liquid chromatography-diode array detector (HPLC-DAD); orthogonal signalcorrection partial least squares discriminate analysis (OPLS-DA); hyperuricemia (HUA); area under the curve (AUC); gas chromatography-mass spectrometer (GCMS); nuclear magnetic resonance (NMR); ultraperformance liquid chromatography-mass spectrometry (UPLC-MS); body mass index (BMI); healthy controls (HCs); systolic blood pressure (SBP); uric acid (UA); glucose (GLU); albumin (ALB); principal component analysis (PCA); Variable Importance in the Projection (VIP); Human Metabolome Database (HMDB); International Union of Pure and Applied Chemistry (IUPAC); adenosine triphosphate (ATP); adenosine diphosphate (ADP); quality control (QC); information-dependent basis (IDA); collision energy (CE); lon Spray Voltage Floating (ISVF); diastolic blood pressure (DBP); white blood cell (WBC); hemoglobin (HGB); platelet (PLT); total protein (TP); alanine aminotransferase (ALT); aspartate aminotransferase (AST); Y-glutamyl transpeptidase (Y-GGT); blood urea nitrogen (BUN);calcium (Ca); phosphorus (P); lactate dehydrogenase (LDH); Triglycerides (TG); total cholesterol (TC); high-density lipoprotein (HDL-C); low-density lipoprotein cholesterol (LDL-C); fold change (FC).

\section{Declarations}

\section{Ethics approval and consent to participate}

Informed consent was obtained from all subjects in accordance with the Declaration of Helsinki. The Medical Ethics Committee of Beijing Lu He Hospital approved all research on human subjects. 


\section{Consent for publication}

All patients provided written informed consent for the publication of information resulting from the results without any personally identifying information.

\section{Availability of data and materials}

All data obtained or analyzed in this study are included in this manuscript and its supplementary information file.

\section{Competing interests}

The authors declare that they have no competing interests.

\section{Funding}

Not applicable.

\section{Authors' contributions}

BZ and LZ designed the project and supervised the work. YW, ZW, and CM recruited patients into the group and collect blood samples. BC and RY analyzed data. JK was responsible for quality control. LY organized the database and specimen library. DZ contributed to project guidance. BZ and CM composed the manuscript. All authors read and approved the final manuscript.

\section{Acknowledgements}

Not applicable.

\section{References}

1. Dalbeth N, Merriman TR, Stamp LK: Gout. Lancet 2016, 388(10055):2039-2052.

2. Pascart T, Liote F: Gout: state of the art after a decade of developments. Rheumatology (Oxford) 2019, 58(1):27-44.

3. Zhu Y, Pandya BJ, Choi HK: Prevalence of gout and hyperuricemia in the US general population: the National Health and Nutrition Examination Survey 2007-2008. Arthritis Rheum 2011, 63(10):3136-3141.

4. McCarty DJ, Hollander JL: Identification of urate crystals in gouty synovial fluid. Ann Intern Med 1961, 54:452-460.

5. Dalbeth N, Phipps-Green A, Frampton C, Neogi T, Taylor WJ, Merriman TR: Relationship between serum urate concentration and clinically evident incident gout: an individual participant data analysis. Ann Rheum Dis 2018, 77(7):1048-1052.

6. Luo Y, Wang L, Peng A, Liu JY: Metabolic profiling of human plasma reveals the activation of 5-lipoxygenase in the acute attack of gouty arthritis. Rheumatology (Oxford) 2019, 58(2):345-351.

7. Li Q, Wei S, Wu D, Wen C, Zhou J: Urinary Metabolomics Study of Patients with Gout Using Gas Chromatography-Mass Spectrometry. Biomed Res Int 2018, 2018:3461572.

8. Luo Y, Wang L, Liu XY, Chen X, Song YX, Li XH, Jiang C, Peng A, Liu JY: Plasma profiling of amino acids distinguishes acute gout from asymptomatic hyperuricemia. Amino Acids 2018, 50(11):1539-1548.

9. Zhang Y, Zhang H, Chang D, Guo F, Pan H, Yang Y: Metabolomics approach by (1)H NMR spectroscopy of serum reveals progression axes for asymptomatic hyperuricemia and gout. Arthritis Res Ther 2018, 20(1):111.

10. Pasikanti KK, Esuvaranathan K, Ho PC, Mahendran R, Kamaraj R, Wu QH, Chiong E, Chan EC: Noninvasive urinary metabonomic diagnosis of human bladder cancer. J Proteome Res 2010, 9(6):2988-2995. 
11. Mahadevan S, Shah SL, Marrie TJ, Slupsky CM: Analysis of metabolomic data using support vector machines. Anal Chem 2008, 80(19):7562-7570.

12. Krishnan E, Akhras KS, Sharma H, Marynchenko M, Wu EQ, Tawk R, Liu J, Shi L: Relative and attributable diabetes risk associated with hyperuricemia in US veterans with gout. QJM 2013, 106(8):721-729.

13. Bhole V, Choi JW, Kim SW, de Vera M, Choi H: Serum uric acid levels and the risk of type 2 diabetes: a prospective study. Am J Med 2010, 123(10):957-961.

14. Juraschek SP, McAdams-Demarco M, Miller ER, Gelber AC, Maynard JW, Pankow JS, Young H, Coresh J, Selvin E: Temporal relationship between uric acid concentration and risk of diabetes in a community-based study population. Am J Epidemiol 2014, 179(6):684-691.

15. Liu J, Tao L, Zhao Z, Mu Y, Zou D, Zhang J, Guo X: Two-Year Changes in Hyperuricemia and Risk of Diabetes: A Five-Year Prospective Cohort Study. J Diabetes Res 2018, 2018:6905720.

\section{Figures}

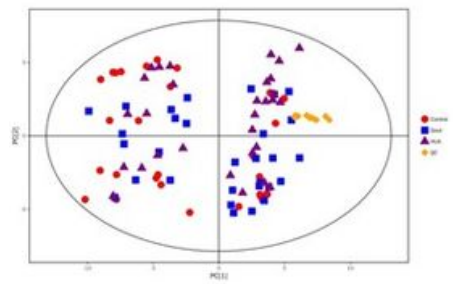

a. Total with QC PCA score plot( positive ion model )

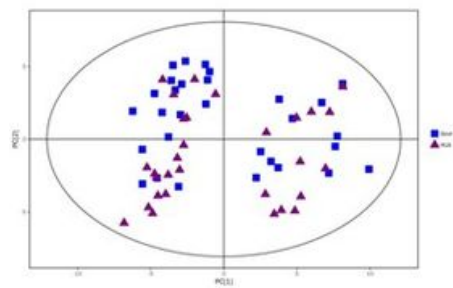

e. Gout-HUA PCA score plot(positive ion model )

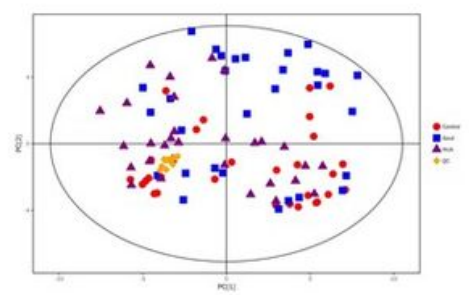

b. Total with QC PCA score plot(negative ion model )

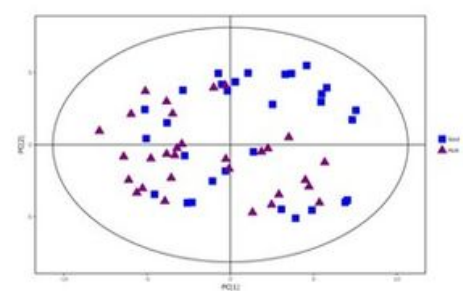

f. Gout-HUA PCA score plot(negative ion model )

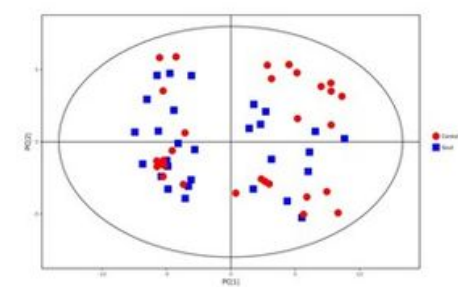

c. Gout-control PCA score plot(positive ion model )

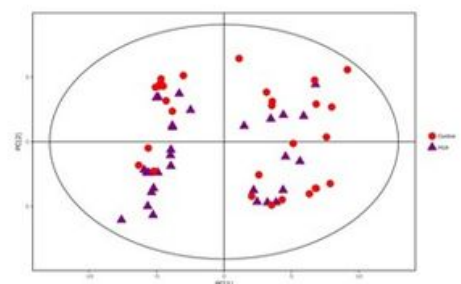

g. HUA-Control PCA score plot(positive ion model )

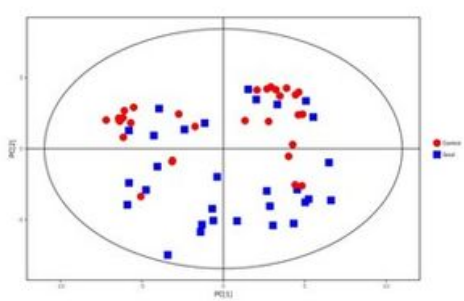

d. Gout-control PCA score plot(negative ion model )

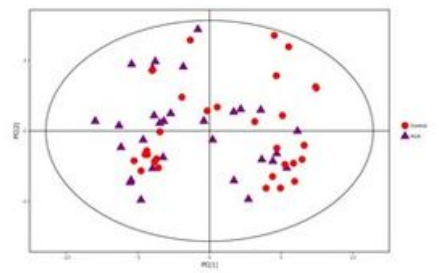

h. HUA-Control PCA score plot(negative ion model )

\section{Figure 1}

The PCA scatter plots were based on the plasma metabolic profiles in positive ion mode and negative ion mode 


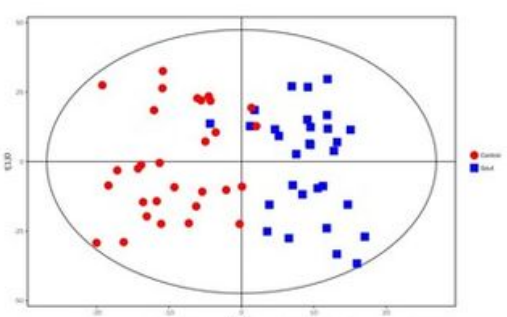

a. Gout-Control OPLS-DA score plot(positive ion model )

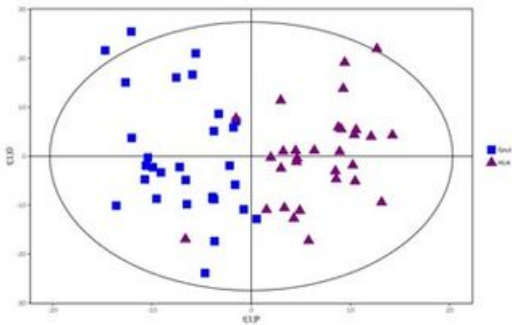

d. Gout-HUA OPLS-DA score plot(negative ion model )

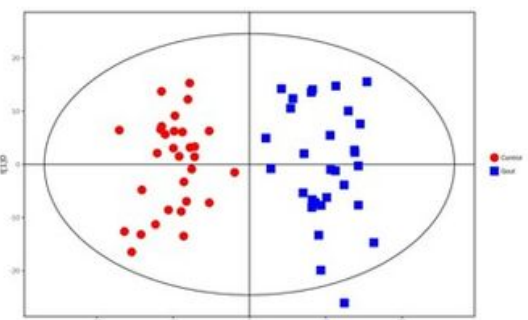

b. Gout-Control OPLS-DA score plot(negative ion model )

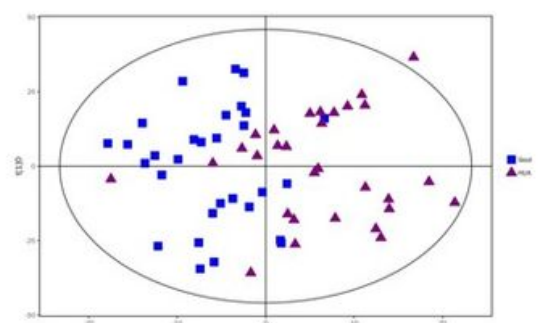

c. Gout-HUA OPLS-DA score plot(positive ion model )

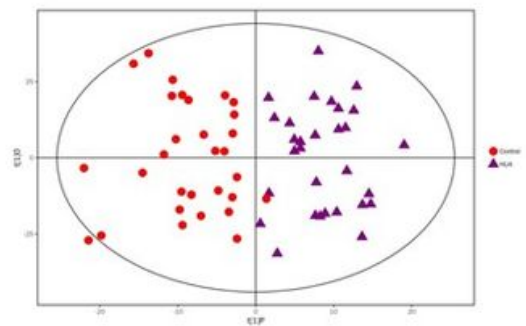

e. HUA-Control OPLS-DA score plot(positive ion model )

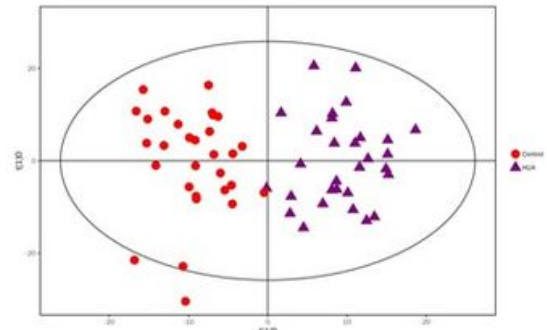

f. HUA-Control OPLS-DA score plot(negative ion model )

Figure 2

The OPLS-DA scatter plots were based on the serum metabolic profiles in positive ion mode and negative ion mode
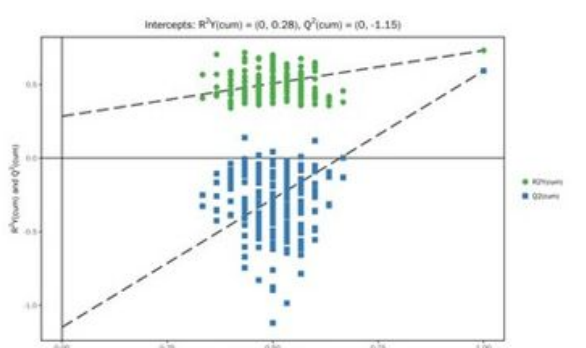

g. Gout-Control OPLS-DA
plot(positive ion model )

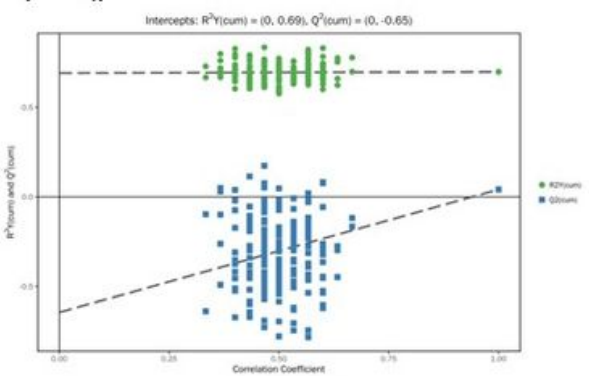

j. Gout-HUA OPLS-DA permutation plot(negative ion model )
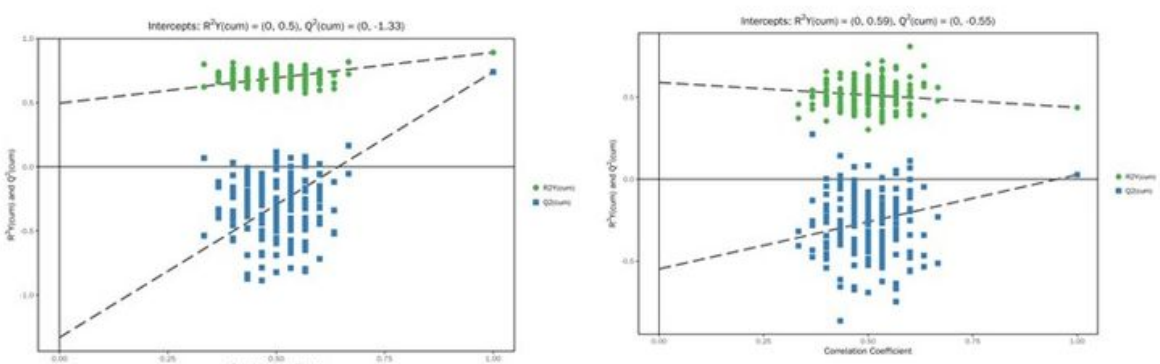

h. Gout-Control OPLS-DA permutation i. Gout-HUA OPLS-DA permutatior plot(negative ion model )

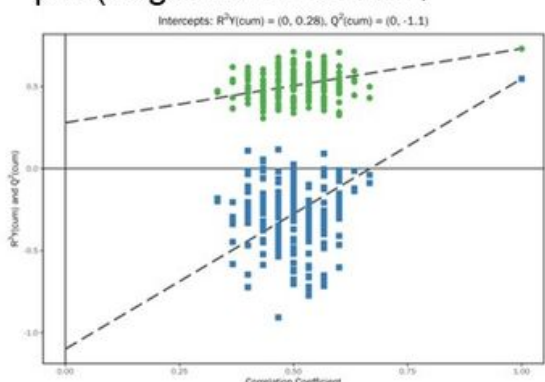

k. HUA-Control OPLS-DA permutation plot(positive ion model )

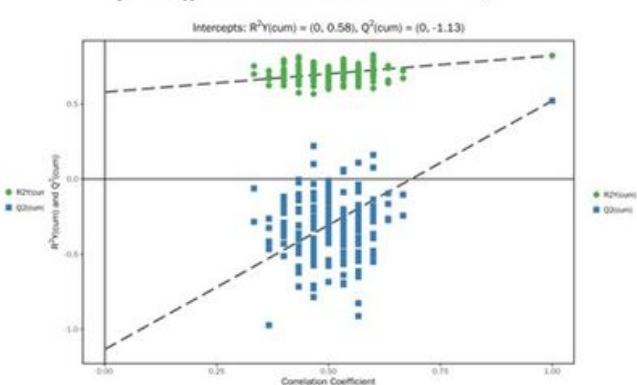

I. HUA-Control OPLS-DA permutation plot(negative ion model )

Figure 3 


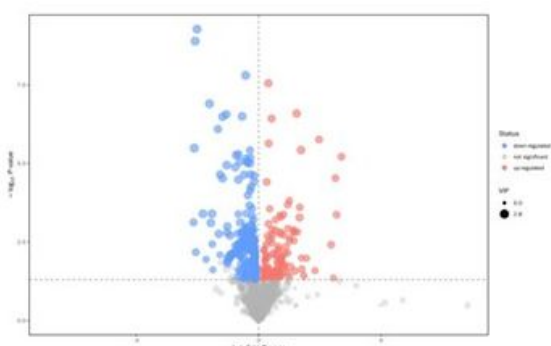

a. Gout-Control volcano plot((positive ion model )

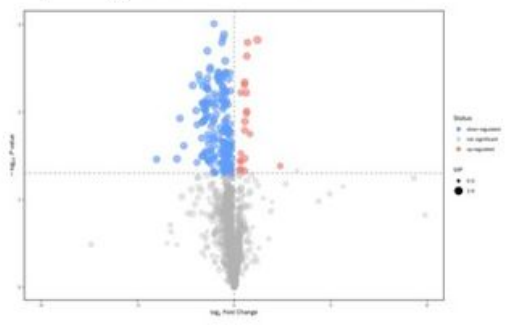

\section{d. Gout-HUA volcano plot(negative ion model )}

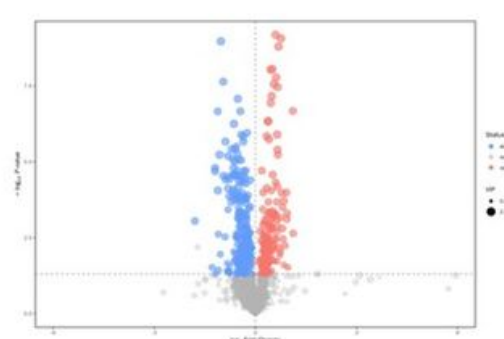

b. Gout-Control volcano plot((negative ion model )

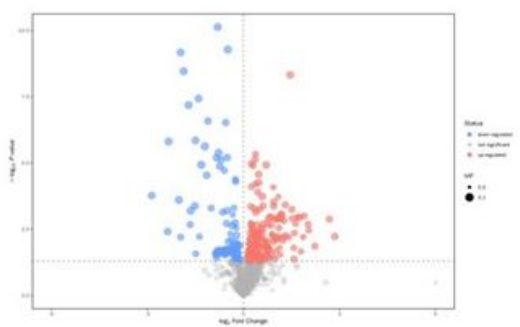

e. HUA-Control volcano plot(positive ion model )

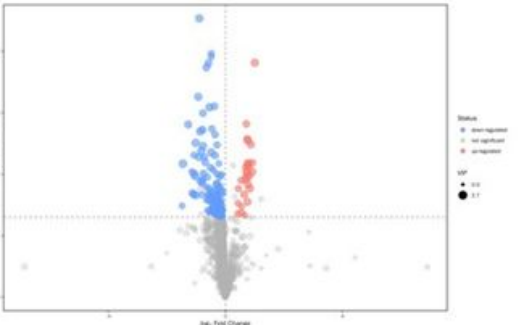

c. Gout-HUA volcano plot(positive ion model )

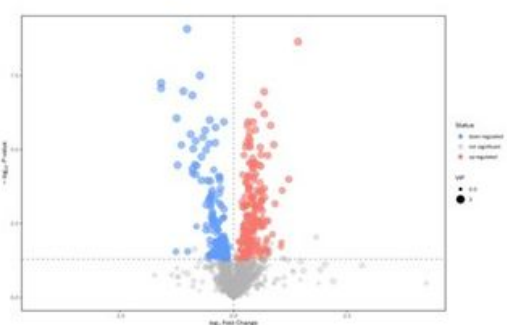

f. HUA-Control volcano plot(negative ion model )

Figure 4

Plasma metabolite differences show in volcano plot

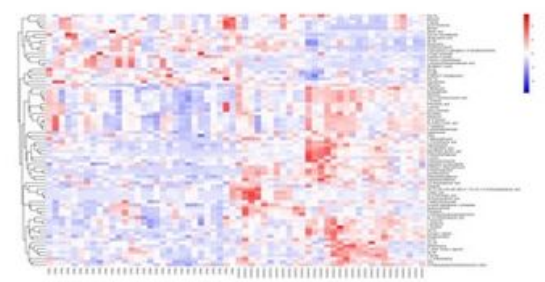

a. Gout-Control hierarchical clustering heatmap(positive ion model )

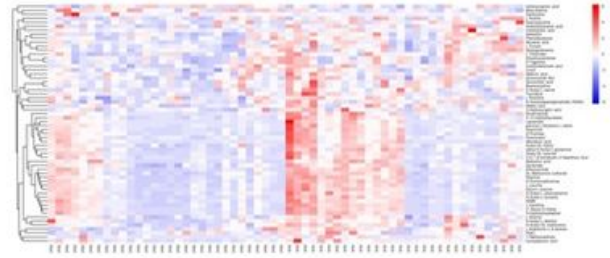

d. Gout-HUA hierarchical clustering heatmap(negative ion model )

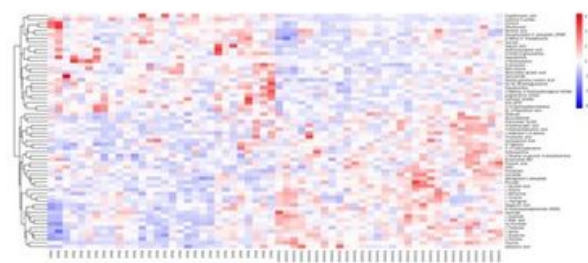

b. Gout-Control hierarchical clustering heatmap(negative ion model )

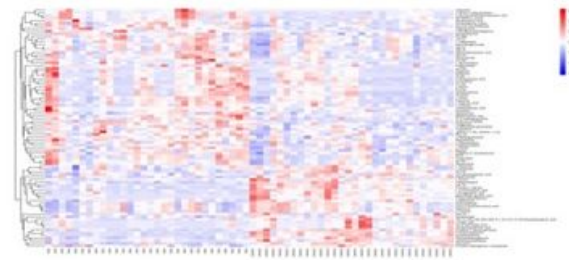

e. HUA-Control hierarchical clustering heatmap(positive ion model )

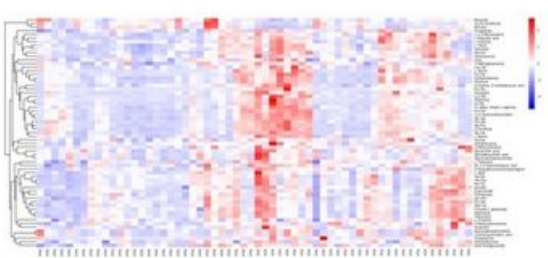

c. Gout-HUA hierarchical clustering heatmap(positive ion model )

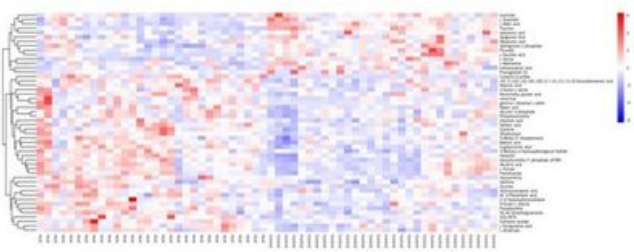

f. HUA-Control hierarchical clustering heatmap(negative ion model ) 
Plasma metabolite differences Hierarchical Clustering Analysis

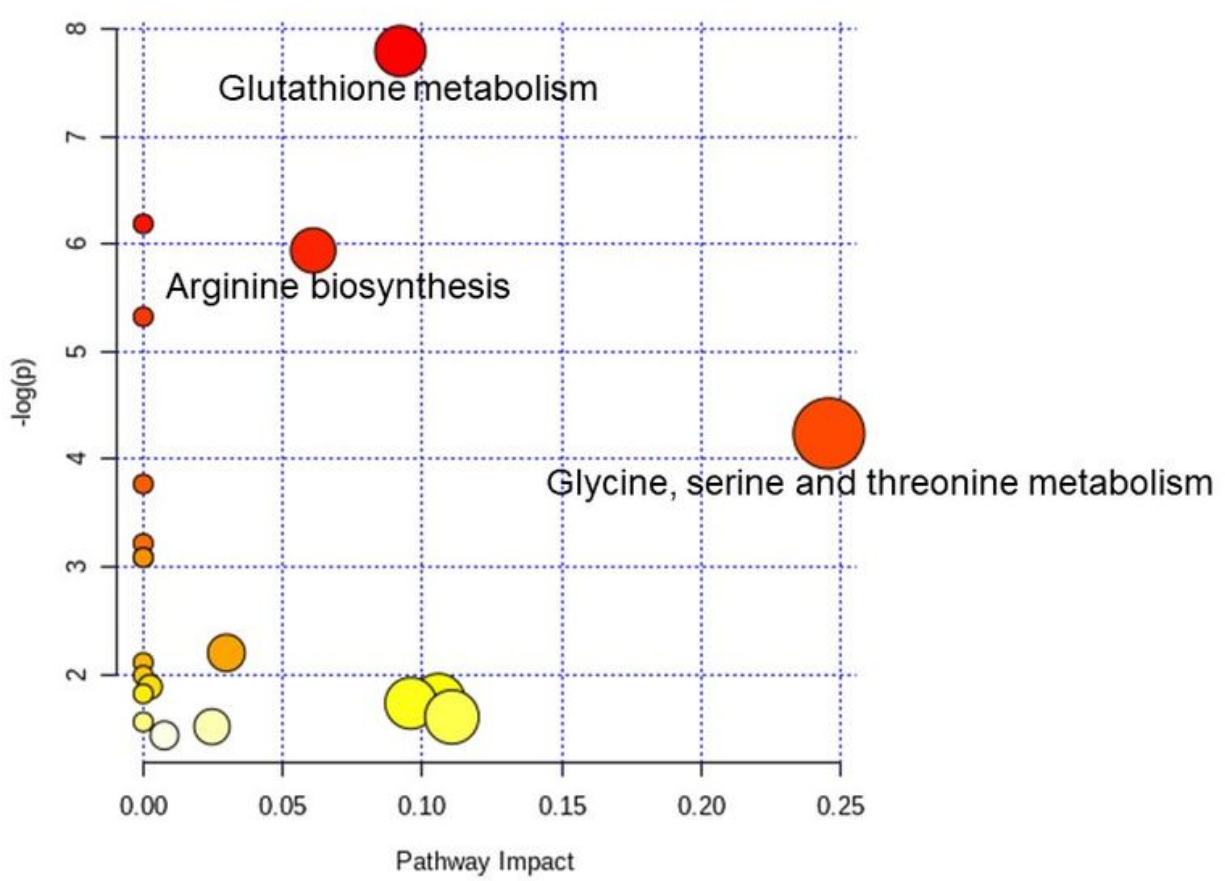

\section{Figure 6}

Overview of metabolic pathway analysis of Gout-control (MetaboAnalyst 4.0). 